\title{
UNDERSTANDING PORTRAYED MENTAL DISABILITY AND SOCIAL DISTRESS IN YOUNG ADULT LITERATURE AND ITS IMPACT: A THEMATIC ANALYSIS
}

\author{
Awaisha Inayat \\ Saima Masoom Ali** \\ Ghazal Khawaja***
}

\begin{abstract}
Young adult literature has been studied to understand how authors represent characters who denotes their version of experiencing mental disability or social distress. Thus the following thematic analysis of young adult novels points a question, that whether portrayal of mental disability/social distress is empowering or not. Certainly, mental disabilities seem to be different in novels: in their attempts to represent mental disability/social distress as a real experience, they're sometimes also attached to popular conceptions of protagonist's love-affair. Hence, to focus on novels representing mental disability/social distress; themes are hypothesized to explore the identity of the protagonist, society's influence on protagonist and whether novel romanticize or represents realistic portrayal of disability/distress. Six novels have been selected-One memory of Flora Banks, Everything-Everything, All the Bright Places, 13 Reasons Why, When we Collided and Will Grayson, Will Grayson. These novels calls attention towards how society aggravates disability and shun those who don't meet certain expectations to be mentally healthy. Literature is a powerful social force and conversation starter about disability/distress awareness to address and deal with challenges. Thus it's important to recognize that it plays a key role in the empowerment and appreciation for disability which has been the center of this analysis.
\end{abstract}

Keywords: Young adult literature, mental disability, social distress, stigma, empowerment, mental health awareness

\section{Introduction}

Mentally disability calls for different kind of understanding for its needs and perspective than what is considered to be normal. Nevertheless across the globe mentally disabled people are dealt as though they should be sorry for existing with a disability ${ }^{1,2}$. Considering this perspective, young adult literature has been studied to understand how authors represent characters who denotes their version of expereincing mental disability or social distress. Thus the following thematic analysis of young adult novels raises a question, is portrayed mental disability or social distress empowering? Furthermore, how disability or distress is related to protagonist's life, and importantly, considered as a burden or meaningful expereince.

* Awaisha Inayat, MPhil Scholar, Department of Psychology, University of Karachi

** Saima Masoom Ali, Ph.D. Assistant Professor, Department of Psychology, University of Karachi

*** Ghazal Khawaja, Ph.D. Assistant Professor, Department of Public Administration, University of Karachi

${ }^{1}$ Dolmage, Jay Timothy. Disability Rhetoric. Ebook ed. Syracuse University Press, 2013

${ }^{2}$ Lewiecki, Wilson Cynthia. "Rethinking Rhetoric through Mental Disabilities." Rhetoric Review (JSTOR), 22, no. 2 (2003): 156-167. 
Young adult novels represent mental disabilities or social issues such as bipolar disorder, suicide and child abuse specifically focusing on the influential role of a society. Young Adult genre use symbolic combination of sarcasm and seriousness to criticize prevailed misconception that disability/distress is unsolicited and unbearable where as also signifying how this perspective can be empowering ${ }^{34}$.

Every disability has some degree of stigma attached irrespective of cultures comprehensively however mental disability or social distress holds distinctive biases in particular. In a factually-oriented scientific world things unseen are subject of suspicion. A substantial emphasis on empiricism in a prevailing visually oriented culture; it's easier to convey "I don't have a leg" than to convey how one experience the world ${ }^{5}$. As it happens, mental disability is generally caught differently in novels: often baffled in an attempt to voice disability/distress as a meaningful real life experience, they're also attached to mainstream protagonist's love-affair or teenage relationship. Hence, thematic analysis also centers on whether young adult literature romanticize the disability/distress or address society's susceptibility to do so.

Young Adult literature facilitates an ideal opportunity to examine ourselves in context of our interests, issues and global challenges reflecting contemporary fears and future concern. This is similar to Bishop's ${ }^{6}$ concept of books as windows or mirrors. Bishop states that book serve as mirror when reader finds it familiar to the world they have experienced. Reader identifies himself as not being isolated in his lived experience. However, novels unlike reader's experiences are termed as windows in which there's an opportunity to look through other people's life with an understanding what it is like to be someone else. Windows and mirrors create ways for readers of all levels of mental health or social issues to either acknowledge their experience or to be aware of people's life in an abusive environment or with mental pathology. The growing number of novels being published that portrays disabled or distressed protagonists highlights an existing interest and demand for a discussion about disability, offering a large platform with diverse perspectives.

\section{Methodology: A conceptual framework for analysis of portrayed mental disability and social distress in Young Adult Literature}

In order to develop a framework, the consistency in which protagonist dealt with issues of identity, influence of society and romanticization of the portrayed issue were considered. Six novels were selected which provided an opportunity to examine the framework in more detail. The novels include: The One Memory of Flora Banks by Emily Barr, Everything, Everything by Nicola Yoon, Thirteen Reasons Why by Jay Asher, All the Bright Places by Jennifer Niven, When we Collided by Emery Lord and Will Grayson, Will Grayson by John Green. For each specific theme, specific questions have been posed which serves as a foundation for analysis. The framework however,

\footnotetext{
${ }^{3}$ Dunn, Patricia A. Disabling Characters: Representations of Disability in Young Adult Literature. Peter Lang, 2015.

${ }_{5}^{4}$ Dolmage, Jay Timothy. Disability Rhetoric. Ebook ed. Syracuse University Press, 2013

${ }^{5}$ Lewiecki, Wilson Cynthia. "Rethinking Rhetoric through Mental Disabilities." Rhetoric Review (JSTOR) 22, no. 2 (2003): 156-167.

${ }^{6}$ Bishop, Rudine Sims. "Mirros, Windows and Sliding Doors." Perspectives: Choosing and Using Books for the Classroom 6, no. 3 (1990).
} 
Doesn't label a novel as good or bad portrayal of disability or distress since no novel is perfect or erroneous. In fact the emphasis is on the degree of effectiveness in representing empowerment, intensity and diversity within disability or distress itself. The following figure represents the framework for thematic analysis.

\section{Identity of Protagonist}

Presenting characters to readers who embrace disabled/distressed identity exhibits significance of valuing diversity in ability than to hide it. The complication in an attempt to define identity arises due to scientific as well as social factor. For example, there is a standardized manual for psychological disorders provided by American Psychological Association called DSM- ${ }^{7}$ (Diagnostic and Statistical Manual of Mental Disorders-5) whereas socially the disability is given meaning by society which is negative in nature and with disabling effects ${ }^{8} 9$. Still identity is an integral starting point for analyzing representation of portrayed disability/distress by viewing oneself and one's relationship to the society, influenced by personal as well as social aspects. In order to evaluate the role of language to construct disabled/distressed perspective, the protagonists are examined the way they reveal their disabilities to readers or other characters in novels. Furthermore, their representation through language and conversations in the novel can be considered to verbally affirm the importance of their perspective. To explore the following; two novels have been analysed The One Memory of Flora Banks ${ }^{10}$ presented Amensia or Everything, Everything ${ }^{11}$ presented SCID (severe combined immunodeficiency- a rare physical disability) to establish their protagonist as unique and valueable.

\section{Society's Influence on Disabled/Distressed Protagonist}

Trites $^{12}$ refers large part to power of institutions in society such as family and other forces shape adolescents and young adults. In the process of identifying disability/distress, it is generally considered how helpful society is to help protagonist in reaching out for help through mental health associations for example school counselor or any other form of support from family. Thus, the following objective is established; what's the role of institution in a society? Do they help or harm characters? In "All the bright places ${ }^{13}$, for both the characters home which is a basic institution of a society is not a bright place or in Thirteen Reasons Why ${ }^{14}$ where the passive role of such instutions can be seen.

\footnotetext{
${ }^{7}$ Diagnostic and statistical manual of mental disorders. 5th. Arlington, VA: American Psychiatric Publishing, 2013.

${ }^{8}$ Corker, Mairian, and Tom Shakespeare, . Disability/Postmodernity: Embodying Disability Theory. 2006. Continuum, 2002.

${ }^{9}$ Donaldson, Elizabeth J. "The Corpus of the Madwoman: Toward a Feminist Disability Studies Theory of Embodiment and Mental Illness." Feminist Disability Studies (JSTOR) 14, no. 3 (Autumn 2002): 99-119.

${ }^{10}$ Barr, Emily. The One Memory of Flora Banks. Penguin Books, 2017.

${ }^{11}$ Yoon, Nicola. Everything, Everything. Delacorte Books for Young Readers, 2015.

${ }^{12}$ Trites, Roberta Seelinger. Disturbing the Universe: Power and Repression in Adolescent Literature. (University of Iowa Press, 2000)

${ }^{13}$ Niven, Jennifer. All The Bright Places. Knopf, 2015.

${ }^{14}$ Asher, Jay. Thirteen Reasons Why. (New York: Penguin Group, 2007).
} 


\section{Romanticization or Realistic Portrayals of Mental Disability or Social Distress}

Elman ${ }^{15}$ precisely criticize the tendency to romanticize mental illness or social distress which makes it seems an alluring trait to attract a romantic partner. This does not take into consideration the impact disability or distress has on everyday life. For instance, if every distressed/disable character in a young adult novel is a poet or an artist, then the entire expereince seems so attractive that a reader might not ask for help if they are in similar circumstances. This also makes the entire perspective of disability as pleasureable which might make it difficult for disabled people to ask for help. On the other hand realist perspective to acknowledge challenges and biases that disable or distress peoople face provides a rich appreciaton and mirror reflection to readers that they do not have to be super disable to be valued ${ }^{16}{ }^{17}$. It's important to empower a disable characters where they feel free to discuss the fear or negative bodily reactions accompanied by crying, panic attack, hatred of suicidal impulses and where characters want their distress/disability to be lessened doesn't imply that they're disowning it. The following objectives are established; do novel romanticize mental illness or social distress or address society's susceptibility to do so and whether realistic portrayal is empowering or not. Will Grayson, Will Grayson ${ }^{18}$ and When We Collided ${ }^{19}$ allowed their protagnoists to express their hatred for aspects of having a disability, yet both display the pleasureable moments of everyday life.

The themes emerged in Young adult literature offer substantial areas to help and motivate a reader to develop an insight about how efficiently issues are depicted in a novel. Besides, it also helps explore where authors have either exploit or empower by reducing the attached stigma regarding spoken issue. Recently, several young adult literatures have been adapted on electronic media increasing its accessibility, availability and preference. Hence, it's important to explore whether depicted disabled/distressed is desirable for the impressionable young adult or adolescent audience especially who go through identity crises. Reading is recommended and encouraged otherwise, then, whether such novels require adult supervision to ensure healthy emotional and social development relevant to norms of Pakistani culture. Besides, how insightful and enlightening are these portrayed disabilities/distress for professionals who're dealing adolescents/young adult age group directly or indirectly.

\footnotetext{
${ }^{15}$ Elman, Julie Passanante. "Cryin' and Dyin' in the Age of Aliteracy: Romancing Teen Sick-Lit." Chronic Youth Disability, Sexuality and US Media Culture of Rehabilitation (NYU Press), 2014: 93-130.

${ }^{16}$ Dunn, Patricia A. Disabling Characters: Representations of Disability in Young Adult Literature. Peter Lang, 2015.

${ }^{17}$ Dolmage, Jay Timothy. Disability Rhetoric. Ebook ed. (Syracuse University Press, 2013)

${ }^{18}$ Green, John, and David Levithan. Will Grayson, Will Grayson. Speak-Penguin, 2010.

${ }^{19}$ Lord, Emery. When We Collided. (Bloomsbury, 2016).
} 


\section{Thematic Analysis Identity of a Protagonist Is Disability/Distress Central to Identity?}

The One Memory of Flora Bank ${ }^{20}$ : Flora Banks a 17 year old girl suffering from Anterograde Amnesia. She had her tumor operated at the age of 10 due to which she forgets everything after every hours. She has memory of her best friend Paige, her stepbrother and parents intact because these are memories before age of 10. Otherwise, she writes basic things to help her remember. Novel begins with Flora attending a farewell of Paige's boyfriend who is moving to Svalbard. However, after a party she ended up kissing Paige's boyfriend Drake and the memory of kissing remained intact. Her parents had to fly to France to look after his brother dying of cancer and they thought they have left her in care of Paige. However Paige was crossed at Flora for kissing Drake and refused to look after her whom Flora kept from her parents hence lived on her own. During this time she got in touch with Drake over email where they both had intimate conversations. After exchange of few emails she decided to meet Drake and travel all the way to Svalbard. Flora in all her certainity kneew that this is the first step claiming her life. It takes her a while to find Drake who instantly denied the kissing and exchange of emails blaming it on her memory issues and even longer time for her parents to even find out that she isn't at home.

Everything, Everything ${ }^{21}$ : Madeline Whittier is allergic to everything, everything because she is suffering from SCID (Severe Combined Immunodeficiency) an illness she's born with. Her world consists of Skype based tutors, several books; creative alternates to board games and movie night with her mother. She has a perfect mother-daughter relationship. Her brother and father died in a fatal car accident. However, story took turn when neighbors (Oliver) moved in next door. The teens began to instant message each other and ended up meeting in Madeline's place with the help of her nurse, Clara. Clara was let go as soon as her mother finds out but it was too late since Oliver and Madeline ran off in spending whatever time they had. To Madeline's knowledge, if she were to go outside, she would only have a few days. Consequently, she gets sick and is forced to return home. Incidentally, once she is back home again, she became like typical teen: resentful of the circumstances set before her, her mother.

\section{How do Language Help Construct Identity about Disability/Distress?}

In One Memory of Flora Banks, the identity of Amnesia was shaky when more often Flora acts like a normal 17 year old teenager in love. She did regress to being a 10 year old girl later in book. However later in book it was revealed that Flora did not have Brain tumor or amnesia instead she and her step brother were in a car accident when she was 10 and her mother felt so guilty about the car accident that she kept drugging her to keep her compliant. Her father who was not in favor of drugs didn't protest either against it. Flora's mother never drove again because of the trauma she suffered. This was revealed with the help of her dying brother on her $18^{\text {th }}$ birthday.

\footnotetext{
${ }^{20}$ Barr, Emily. The One Memory of Flora Banks. (Penguin Books, 2017)

${ }^{21}$ Yoon, Nicola. Everything, Everything. (Delacorte Books for Young Readers, 2015)
} 
In Everything, Everything; As the book unfolds the story, it reveals that Madeline just has a weakened immune system from her mother's abuse of keeping her locked in a bubble house for eighteen years in response to her father and brother's traumatic deaths in a car accident. She imposed a disease SCID (Severe Combined Immunodeficiency) on her child, making sure she's protected, closed and every activity is right under her nose.

The One Memory of Flora Banks which gives protagonist the identity of Amnesia and Everything, Everything which gives the identity of SCID (Severe Combined Immunodeficiency) points mental pathology like FDIA (factitious Disorder Imposed on Another) ${ }^{22}$ and social distress of a child abuse at the expense of reproaching the actual disability which was an identity of a protagonist.

There is capable narrative in all its horrible glory in both the books, in other words novels can't have a happy ending if protagonist is actually disabled. Happy endings come to the stable-minded or well-bodied. The relationship of Flora with Drake which eventually became a corridor leading to finding the truth or Oliver who loved Madeline even when he thought everything could kill her, but the happy ending still keeps the stigma attached and novel itself not being vocal about the disability. Instead it was wrapped with a social distress, that both the girls were trapped in house for years, simply a victim of traumatized-pathological mother. Disability is not just a romantic hurdle to get over, nor is it a guarantee of bad parenting. Characters with disabilities get little enough representation, and when a disability that could conceivably work against the love and sex life of a disabled character happens, it feels rather insulting to not show any work towards those issues that real disabled people might face. Instead hand-waving all their issues for the happy ending especially that comes at the expense of scapegoating another disability. Conclusively, the identity shown was not central to the portrayed disability rather it also weakened the vocal expression of a distress like Child abuse at the hands of mothers with a wrap up of teenage love successful or unsuccessful love relationship.

\section{Society's Influence on Protagonist's Distress/Disability What is institution's role in a society (for instance; family)-does it help or harm the protagonists?}

All the Bright Places ${ }^{23}$ touches upon neglected parenting and how the complete absence of parenting causes a distorted image-of-self. Throughout the novel, Finch suffers from Bipolar Disorder, yet is given no help from his divorced parents. Finch conceives in his mind his father wants nothing to do with him and has already replaced his children with his second wife's kids. In his father's words:

What did you think would happen? Damn right he's a delinquent, and a criminal, and an emotional wreck, and a major-disappointment-weirdo.... Be grateful for your daughter, sir, because trust me, you would not want my son. No one does.

Finch creates an identity of being replaceable based on his relationship and interactions with his father. When Finch kills himself, his father acts completely shocked, showing

${ }^{22}$ Diagnostic and statistical manual of mental disorders. 5th. Arlington, (VA: American Psychiatric Publishing, 2013)

${ }^{23}$ Niven, Jennifer. All The Bright Places. (Knopf, 2015) 
how far removed he is from Finch's life and feelings. He allows his identity to be shaped by his father instead of turning to other relationships to see how he could mold his identity based on interactions with people who truly care about him, like Violet. This shows the power of parental interactions and how characters take their parental figure's views of them seriously and form their identity based on their interactions with these figures, either positively or negatively. In Finch's case it was definitely negative.

Violet in All the Bright Places also recognizes the importance of parental guidance and supervision. After losing her sister in a car accident, Violet is lost in life and only goes through the motions day by day. Her parents' sense these directionless and hopeless attributes because Violet used to be optimistic, involved in many extra-curricular activities and always spending time with her friends. Violet feels like she lives in a different world from her parents until Finch helps her realize what her parents' love actually means.

For most of the novel, Violet cannot understand why her parents are so obsessed with her well-being and wanting to make sure she leaves the house and starts writing again like she used to. How invested her parents are in making Violet happy again is apparent to Violet by the end of the novel and she begins to mold her sense-of-self off of her parents once Finch has died. By understanding how to love unconditionally, even in desperate situations when no amount of help seems to be the answer, Violet sees how the parental role creates an identity in her and the children of other parents. Violet places herself in the shoes of her parents and creates a sympathetic identity that contrasts her initial belief that no one could help her or understand her sadness in the loss of her sister. She can now comprehend what it means to be a parent and love so selflessly, even in the midst of tragedy and when that love is not reciprocated. Even in seemingly hopeless situations, Violet still conveys love because of the love she is shown by her own parents.

Parental interactions and family as institutions in society are pivotal in a young adult's life because every character has parents, whether present or not. Parental interactions can be easily understood by the reader because of the universal notion that everyone has a set of parents. Parental failures to attend their children are not only limited to the aspect of understanding them but are also tied to the economic (formal institution) challenges that plagues middle class family described in 13 Reasons Why. ${ }^{24}$

In the book 13 Reasons Why Hannah Baker is a white middle class high school student who suicide. She as one half of novel's two voiced narrative explains her reason for suicide and possible role people played in their suicide through cassette tapes she had emailed before suicide.

Clay who is the first recipient of the tapes confuses him because he believes he has always been a good friend to Hannah. As Clay looks for answers for her suicide, Hannah's story of bullying behavior and exclusion raises questions about complicity and the consequences of cruelty.

In her taped-retelling of her decision to suicide, Hannah also mentions the financial pressure her parents face when their business begins to fail. Though her tapes make clear

${ }^{24}$ Asher, Jay. Thirteen Reasons Why. (New York: Penguin Group, 2007) 
that many factors, and people, led her to suicide this distance with her parents makes such issues all that much harder to bear. When her mother fails to notice the haircut, she connects this with other examples in the novel where people have failed to see her, see her pain and offer help.

Parent-child relationships in all of the novels reflect contrasting intentions: these young protagonists crave parental love, devotion, involvement, and admit they need it. Whereas they also push parents away to figure life out on their own while also believing that parents are misfit in their social worlds, "the real world" that they reside in is far from the love and protection of parents and home.

Adolescence is a period of human life when the brain, still more intensively than before, learns to recognize and attribute mental states to ourselves as well as other people. $^{25}$

The unpredictability of the adolescent stage in life is very much a product of how we are raised and the society that brought us up. Parents contribute to this atmosphere immensely with their interactions or lack of interactions. Attributing mental states deals with identity in that image-of-self is formed by how these interactions with parental figures either build up or destroy self-image.

\section{Romanticized or Realistic Portrayal of Disable/Distressed Protagonist}

The analysis so far has laid an important framework to examine empowering representations of mental disability/social distress in young adult literature, but readers must also look at how individual novels allow disabled people a full range of expression, including a discussion of struggles they face because of mental effects of disability or social distress. This does not mean that disabled or distress people are disempoweredinstead, it means that they can manage their lives with all the challenges. However such realistic portrayals are relatively rarely seen in Young Adult Genre. Instead portrayal of distress or disability are frequently romanticized which has the potential to silence those who experience pain, discomfort and displeasure.

\section{Does the novel romanticize distress/disability or address society's tendency to do so?}

In the book Will Grayson, Will Grayson ${ }^{26}$ each create a character named Will Grayson, and the novel alternates between the two Wills' perspectives. Green's Will tries hard to be tolerant and sensible as a hilarious counterbalance to his best friend, Tiny Cooper. Their friendship is incredibly endearing, and the two friends eventually meet Levithan's Will, a teen who has a dark sense of humor, as well as depression. Unlike most of the novels presented, Will Grayson, Will Grayson does not make disability its main focal point, although depression does influence the way Levithan's Will interacts with others and perceives himself. His diagnosis seems to be in the distant past, while the more noteworthy event at the beginning of the novel is that he has just been heartbroken by a fake Internet boyfriend. Levithan's Will had fallen in love with Isaac online and arranged to meet him for the first time in Chicago, only to find out that his friend Maura created the persona to try to force Will to admit he is gay.

${ }^{25}$ Nikolajeva, N. "Theory, Post Theory and aetonormative theory." Neohelicon, 2009: 13-24.

${ }^{26}$ Green, John, and David Levithan. Will Grayson, Will Grayson. (Speak-Penguin, 2010) 
Levithan's Will and Tiny break up after a fight in which both are guilty of minimizing the other's struggles: Tiny fails to comprehend the scope of Will's depression, and Will fails to acknowledge the stress that Tiny is under to express himself and be the big personality that he is. In the end, however, all of the characters reunite to support Tiny's successful musical performance, which celebrates the group's relationships and myriad personalities as well as their conflicts with each other.

Will Grayson, Will Grayson refuse to represent disability as a useful narrative prosthesis simply to add intrigue to the story. When Maura initially confronts Levithan's Will for not telling her he is gay - before revealing herself as Isaac-Will describes that Maura constantly tries to push him into confiding in her, flashing back to the time when she looked through his bag without permission and found his depression medication. This suggests that shame is exactly what Maura is hoping for, as the secretiveness of knowing about Will's depression will link her to him, yet he wants to avoid this conversation not because of guilt but because he does not want Maura to exaggerate or obsess over a challenge with which he has already come to terms.

In examining this friendship, it's also significant to consider how society's tendency to romanticize mental illness might be part of the reason why more people feel like Will and just avoid the topic altogether, as they expect to be misunderstood before they even begin to discuss their experiences. This exchange is particularly important when examining romantic aspect because it shows that Tiny has failed to understand exactly how serious Will's depression is. While on the one hand romance tends to expand the experience of disability to the "secretive" and "sacred", it can also make disability seem trivial since it does not also take into account the real challenges disability causes ${ }^{27}$.

In the book When We Collided ${ }^{28}$ features one of the dynamic characters of young adult literature: Vivi Alexander who in her own words is describes as, full of "fight and art and entire swirling galaxies" (Lord, p 304). Her empowering quotes throughout the novel promote a positive self-love. She is also wonderfully unapologetic about both her personality and her disability.

Vivi had been diagnosed with bipolar II disorder before the events of the story took place, though readers do not know this until after several chapters. Visiting Verona Cove for the summer, she meets Jonah Daniels, and the two quickly fall in love. It certainly begins with the rather typical summer love story, complete with an instant connection, dramatic gestures of love to celebrate Vivi's birthday. Yet novel also goes deeper into an exploration of mental health that takes precedence over the admittedly addictive love story. In fact, Vivi is not the only one with a disability. Jonah's large family is recovering from the loss of his father, and his mother has had a particularly difficult time dealing with it. Throughout the story, Jonah worries that her grief has turned into clinical depression since she has seldom left her room in the past six months, while responsibility for running the home and family restaurant shifts to Jonah and his older siblings.

\footnotetext{
${ }^{27}$ Donaldson, Elizabeth J. "The Corpus of the Madwoman: Toward a Feminist Disability Studies Theory of Embodiment and Mental Illness." Feminist Disability Studies (JSTOR) 14, no. 3 (Autumn 2002): 99-119.

${ }^{28}$ Lord, Emery. When We Collided. (Bloomsbury, 2016).
} 
As Vivi and Jonah begin dating, her energetic personality wins the hearts of his siblings, and the two explore their relationship, Jonah's grief, and various family struggles. Vivi's more obvious mania begins after she decides to find and contact her father, whom she has never met before. When she realizes that he has had an entire life-complete with wife and children - without ever trying to get to know her, she understandably struggles to come to terms with her discovery. This encounter is not necessarily the cause of Vivi's mania, as she had suddenly bought a Vespa a few days before spontaneous decisions being another suggestion of mania but it does contribute to the extremes of Vivi's emotions, resulting in a few days of sadness followed by another mood shift. She ends up crashing her Vespa, resulting in an emergency trip to the hospital, where her mood is stabilized and her broken arm and ribs are treated. By the end, Vivi and her doctor can loosely recreate the timeline as events which occur before the summer "depression, hypomanic episode in March, depression after the hypomanic episode," - and events during her time in Verona Cove-“"then new medicine and manic again",29

Jonah for the most part accepts Vivi for who she is, without trying to change her although he does argue with her over some of her more overenthusiastic actions. However it effectively reveals the romanticized trope before showing a more empowering alternative, one which does not erase disabled uniqueness but rather supports it.

\section{Does realistic portrayal still allow for an empowered disabled/distressed perspective?}

In the novel Will Grayson, Will Grayson ${ }^{30}$ Another daily feature of depression is the medication Will takes. Will's prescription is mentioned several times throughout sometimes with a joke attached, but the casual yet frequent references allow to subtly remind readers that taking pills is not something that goes on behind the scenes. Instead, it is something which Will cannot forget to do each morning - it is such an important detail that Will remarks he keeps the bottle by his fish tank so that feeding his fish reminds him to take his medicine. Will's sarcasm also manages to find the humor in taking medication, which emphasizes realistic treatment of depression. If depression is entirely prohibited to being included in jokes, then disability is perturbed even more.

It is a prime example of how difficult it can be to distinguish between a romanticizing or realistic portrayal is Will being shamed for taking medication or is he giving voice to a challenge that he must deal with as part of being depressed? Will's loathing of pills could help him reject the feelings of guilt about being disabled, mainly because Will belongs to a society where taking vitamins or birth control every day does not always carry the same negative meanings as depression medication. In his words: "I think the idea of a 'mental health day' is something completely invented by people who have no clue what it's like to have bad mental health. the idea that your mind can be aired out in twenty-four hours is kind of like saying heart disease can be cured if you eat the right breakfast cereal. Mental health days only exist for people who have the luxury of saying 'I don't want to deal with things today' and then take the whole day off, while the rest of us are stuck fighting the fights we always fight..."

\footnotetext{
${ }^{29}$ Lord, Emery. When We Collided. (Bloomsbury, 2016).

${ }^{30}$ Green, John, and David Levithan. Will Grayson, Will Grayson. (Speak-Penguin, 2010)
} 
Most professionals especially psychologists would critically examine how society adds to Will's feeling of hatred for having to take mental health medication regularly and for not overcoming his depression ${ }^{31}{ }^{32}$.Yet it difficult to go beyond the social pressures with depression to examine the fact that perhaps it is inconvenient and challenging for Will to rely on a medication in order to fulfill his quality of life. Throughout the novel, Will is fairly adamant about not caring what people think of him, so the hatred of his pills could be attributed primarily to the obligation of remembering and being tied to something he would rather live without. There is room for both interpretations that this struggle of sarcastically commenting on taking medication one day while loathing it the next truly captures the balance that a young adult novel needs.

These characters have thus achieved balance: without forgetting that hard challenges will always exist, they can still move forward towards making their lives and their world a better place. These characters do not hide behind the presentable or normative moments of their daily lives but are empowered by the entirety of the disabled experience.

In the novel when we Collided ${ }^{33}$, Vivi also directly addresses an instance when Jonah misunderstands the depression of his mother. Recognizing that Jonah views his mother as disempowered because of her illness, Vivi points out his biasness by emphasizing how important it is to listen to disabled people. Though the two ultimately break up when Vivi moves back to Seattle after the summer, neither of them regret their relationship. Vivi decides it must end both because of the distance and because she knows that as she continues to adjust to her bipolar disorder, she cannot be affected by someone else's life. Though heartbreaking to read, Lord (2016) positions the reader to respect and embrace Vivi's decision to place her mental health over a relationship.

\section{Discussion and Implications}

When analyzing contemporary young adult novels, we cannot limit these books to literature instead we are studying our present world, and it is important that this genre reflects our diversity in social issues and mental health challenges with an effort to promote its inclusion. Insightful novels can encourage readers especially psychologists to examine fictional scenarios to better understand the current social factors and distress that shaped such a text. For example, reading All the Bright Places ${ }^{34}$, it will not just give the idea through language about a mentally disturbed person but also helps analyzing how different factors plays destructive role for a person simultaneously. Similarly in 13 Reasons Why ${ }^{35}$, suicide has been highlighted through complete ignorance of institutions like family, school while bullying, and lack of affection. This gives us a window image about individual differences, diversity in cultural norms as well as an insight to details of a character which such a person in real would be unable to speak otherwise.

Instead of keeping mental disability or social distress a stigmatized and a taboo topic, discouraging its discussion at an institutional level (family, schools) would not lessen its

\footnotetext{
${ }^{31}$ Dolmage, Jay Timothy. Disability Rhetoric. Ebook ed. (Syracuse University Press, 2013)

${ }^{32}$ Dunn, Patricia A. Disabling Characters: Representations of Disability in Young Adult Literature. (Peter Lang, 2015).

${ }^{33}$ Lord, Emery. When We Collided. Bloomsbury, 2016. Lord, Emery. When We Collided. (Bloomsbury, 2016).

${ }^{34}$ Niven, Jennifer. All The Bright Places. (Knopf, 2015).

${ }^{35}$ Asher, Jay. Thirteen Reasons Why. (New York: Penguin Group, 2007)
} 
reading rather it will end up in being read and not addressed or supervised. Rather, discussions over social distress through these books will be an excellent way to help address adolescents and young adult issues which otherwise would is difficult to spoke about generally in Pakistani context.

While all readers should be aware of empowering themes in young adult disability novels, students and educators in particular can create more inclusive classrooms by addressing disabilities and challenges associated. One of the concerns for educators, scholars, and authors is their own disability status, particularly if they hope to include a disability perspective but feel unsure about their ability to approach it effectively. The subject of disability is thus an important topic for all students who have encountered societal norms. Literature is also a powerful social force and conversation starter about mental health and distress awareness. Dealing with challenges to one's mental health is thus should not be an occasional experience, and educators have a responsibility to include such perspectives in curriculum. It is thus important to recognize that educators play a key role in the empowerment and appreciation for disability which has been the center of this research.

\section{Limitations}

Like all research, this thematic analysis is not without limitations. The intersection of disability and distress theme within young adult literature is a growing field for researchers, offering many possible avenues for study. However, there are difficulties in comparing amnesia to mood disorder, as these experiences have different neurological and emotional roots, which in turn affects how a character theorizes influence. Though the analysis was an attempt to create solidarity and awareness for a broad spectrum of less visible disabilities, a closer look at individual disabilities and distress could create more focused frameworks in future researches.

In narrowing research from all distress to mental disabilities, smaller selection of books gave room to explore specific challenges that society and mental disability pose for individuals; for instance, analysis of how a less prominent disability prompted moments in protagonist's identity and how mental health medication is both feared and stigmatized. Likewise, a more detailed focus on depression or suicide could reveal common preconceptions about such experiences that are more noticeable when repeated across all books.

The thematic analysis covers some of the most frequent and an important theme in young adult literature, but it is of course not comprehensive. In particular, disability across different cultures for instance fiction portraying same issues by Pakistani authors and portrayals of culture-relevant disability and distress offer rich potential for future analysis. 